DE DE GRUYTER

Research Article OPEN

\title{
The Sustainable Leadership for Vocational Schools in Thailand: A Structural Equation Model
}

\author{
Khukrit Silalaiy \\ Thanin Ratanaolarn \\ Malai Thaveesuk \\ Department of Industrial Education, \\ Faculty of Industrial Education and Technology, \\ King Monkut's Institute of Technology Ladkrabang, Thailand
}

Doi: $10.2478 / \mathrm{mjss}-2018-0050$

\begin{abstract}
The purpose of this research was to study the leaders' characteristics, situation management, behaviors and roles affecting sustainable leadership development and examine the compatibility of the structural equation model regarding sustainable leadership for vocational education administrators, as developed from the empirical evidence and determined influence of each factor. The quantitative research utilized questionnaires, given to a sample of 404 vocational education principals and vice-principals, derived using a multistage sampling method from 413 vocational public schools in Thailand. To test the confirmatory factor analysis and structural equation model were conducted. This research findings suggest that the structural equation models for sustainable leadership development of vocational education administrators were in accordance with the empirical data. The leaders' characteristics factors had the weight of the maximum gross effects towards the sustainable leadership development. This study suggest that the sustainable leadership development for vocational education administrators can be carried out by developing leaders' characteristics.
\end{abstract}

Keywords: Leader, characteristics, situation management, behaviors, roles, sustainable leadership

\section{Introduction}

Through many successive governments, Thailand has historically attempted education reform to no avail. Despite several amendments to curricula, as well as implementation of myriad well-meaning policies, educational outcomes in Thailand have not improved. In 2014, The International Institute for Management Development (IMD) ranked Thailand 54th in 60 countries assessed. Education is a key factor in a nation's competitiveness and as a result, stakeholders from many sectors have expressed concern about Thailand's educational crisis and endeavored to come up with solutions to solve it.

The success of educational reform depends not only on good policies but also on several other factors. Significant among these is the role of school administrators. If administrators have necessary characteristics and skills of leadership, such as demonstrating responsibility for society and the nation, morals, commitment to social development, and abilities to operate quickly, overcome obstacles, understand others, inspire creativity and judge critical issues. Successful leaders see the big picture for the country, possessing a broad vision for where and how to steer their organizations in accordance to both local and global contexts. 
The importance of successfully enacting change to improve organization performance is a critical issue facing today's organizational leaders. Leaders need to formulate an inspirational vision, and effectively communicate the vision via multiple channels to create a sense of readiness for change. By improving change readiness organizations should be able to create initiatives effectively for organizational growth and competitiveness. (MD, et al., 2016).

Leadership is remarkably wide-ranging and complex. For leaders, their relationship to other members in a group is based on eliciting the actions and behaviors necessary to achieve a desired goal. Demonstrating leadership involves both participation and performance, as leaders must display their abilities to compel members of a group to function well, cooperate with one another and complete tasks successfully (Stogdill, 1974). Leaders have a central role in a group and to use their authority as a tool to determine the behaviors of individuals in a group as well as their mutual interactions in support of achieving goals and initiating new projects (Bass, 1985). Leaders wield influence upon others to recognize communal or organizational goals (Hersey, et al., 1996; Lipham, 1998; Stoner and Freeman, 1989) and possess the ability to persuade others into achieving those shared goals effectively (Ellis and Hartley, 2001; Hellriegel et al., 2001; Northouse, 2007) and the capacity to fully support each individual group members' efforts (Yukl, 2010). Hence, leadership is a state in which an individual or individuals can influence or induce others by using their abilities, skills, influences, or inspirations to uniting them in action and spirit, to impel them to act voluntarily, and to instill in them the intention and enthusiasm to be involved in the activities necessary to achieving the goals needed by the leaders to attain desired results for the organization.

Thus, leadership is an essential factor in the effective management of an organization. Educational institutions are organizations with the ultimate goal of developing quality graduates to meet the standards of not just the school and related agencies but also the needs of society, and must also develop leaders to carry out this mission. To achieve the development of said leadership skills, study of the knowledge, abilities and skills required for school administrators considered several theories related to leadership, such as theory based on the characteristics leadership, behavioral leadership, situational leadership and transformational change of leaders.

\section{Theoretical Foundation}

\subsection{Sustainable Leadership}

As leaders must maintain their competencies to develop both individual personnel and the organization as a whole to respond and adapt to the complicated challenges caused by request and context change (Davies, 2007), sustainable leadership helps leaders to be able to improve their knowledge and competencies in the management of human resources and organizational resources, and provides valuable opportunities for leaders in the educational arena to network and support one another in the achievement of not only current but also future organizational goals (Fullan, 2001; Hargreaves \& Fink, 2006), and thus such leadership has great potential to enhance development and bring forth change for the better.

While a strong vision is essential to leadership, sustainable leadership must also incorporate respect for past and awareness of the present in the bid to create a better future. Most theories of educational change and their application focus merely on potential change and future orientation while neglecting to address the significance of the past (Hargreaves and Goodson, 2004). Organizational change affects both the present and future of said organization. Sustainable development benefits from protecting, maintaining, and renewing all the things of value from the past instead of discarding them, and constructive lessons learned from the experiences accumulated through time, including but not limited to culture, tradition, and local wisdoms, will not fade and disappear but instead inform values. Sustainable organizations protect and adhere to their own values to be effective, which enhances learning and development. This is in accordance with the research of Abrahamson (2004) which indicated the benefit of utilizing the past in the shaping of the future. Creating new elements by integrating the previous parts proved more effective and convenient than having to devise entirely new structures and technologies. By being conscious of the past and learning from it, organizations can avoid many foreseeable detriments and pains 
brought about by change.

Sustainable leadership must see to establishing styles and methodologies, increasing personnel competencies and fostering general development through implementing various initiatives, learning environments and focusing on personal change. Creating a sustainable organization and community involves modeling and consultancy, with leadership attributes transferred to subordinates who are given authority through delegation so they too can develop their own leadership and so forth. Hence, the sustainable learning and delegation will create a cycle of leadership development that thrives continuously not only in the present but in the future as well (Grooms \& Reid-Martinez, 2011).

Creation and learning, principles of success, leadership creation for others, justice, development of existing resources, development of diverse environments, and active participation are essential components of sustainable leadership (Hargreaves \& Fink, 2004). To foster sustainability, educational leaders must improve, maintain, and develop education to be learning that is wide-reaching and accessible and that which will cause neither hazard nor harm. Sustainable education creates positive benefits for all, both in the present and future. According to these parameters and the evidence inherent in the research into the components of sustainable development for educational change and sustainable leadership. Hargreaves \& Fink (2006) stated that sustainable leaders develop content or values that are sustainable, construct and develop effective leadership, transfer leadership strategies, promote social justice, create a variety of environments to stimulate creativity, recognize what traditional values and practices are worthy of conservation.

Moreover, Lambert $(2011,2012)$ proposes that sustainable leadership must also include building the capacity of staff, strategic distribution, consolidation, establishing long-term objectives from short term goals, diversity, conservation, and respect for the past in the pursuit of a better future.

\subsection{Leaders' Characteristics}

The characteristics of effective leaders include responsibility, intention to work successfully, strength, effort, knowledge of risk management, initiative, self-confidence, ability to manage stress, ability to influence others, and ability to coordinate all elements towards successful performance (Stogdill, 1981). Additionally, effective leaders should be visionaries, systematic thinkers, innovators, collaborators, educators and advocates, as these are leadership characteristics integral to organizational sustainability. Huglies and Hosfeld (2005) and Visser and Courtice (2011) studied the general characteristics of sustainable leaders, and proposed that, to be sustainably effective, leaders must maintain the following 5 characteristics: 1) be caring and morally-driven, 2) be a systemic and holistic thinker, 3) be enquiring and open-mined, 4) be self-aware and empathetic, and 5) be visionary and courageous. Furthermore, for leaders to develop effectiveness and sustainability, they must learn to possess discipline in the understanding of systems, emotional wisdom, good attitudes focusing on values creation, trust, strong intentions and viewpoints for development and long term effects, and finally, a vision to bring about positive change (Visser, 2013).

\subsection{Situation Management}

Situations create leaders and the factors specific to various situations determine the types of leadership they create. These include the characteristics of organizational structures, environments, personnel and roles (Hoy \& Miskel, 1991). Different situations require different leaders, each with behaviors appropriate to each distinct environment. The effectiveness of leadership depends on the compatibility between the type of leaders and each situation, also taking into account the motivational state of followers (Owens, 1981), as individuals' needs have to be addressed to facilitate the achievement of group or organizational goals (Fiedler \& Chemers, 1974). The success of leaders depends not only on the appropriateness the leaders' behaviors, but also the attitudes of groups or individuals within an organization (Hersey \& Blanchard, 1982). 


\subsection{Leaders' Behaviors}

It is believed that behaviors can be learned or practiced. Leaders can become more effective if trained to have appropriate behaviors, so evidently specific behaviors impact the achievement of group goals (Blake \& Mouton, 1964; Reddin, 1970). Leaders' behaviors are considered the medium of relationship between the characteristics of leaders and their effectiveness. The components of leadership behaviors are covered in 3 dimensions as follows: the Task-Oriented Dimension, the People-Oriented Dimension, and the Change Dimension (DeRue et al., 2011).

\subsection{Roles of Leader}

Roles of leader consist of pathfinding, aligning, empowering, and being a role model (Covey, 2004; Knezevich, 1984). For educational institutions, it is necessary for leaders to have competencies in the following roles: direction setter, catalyst, planner, decision maker, organizer, change manager, coordinator, communicator, conflict manager, problems manager, systems manager, instruction manager, personal manager, resource manager, appraiser, public relator, administrator, academic instructor, disciplinarian, human relations counselor, assessor, problem solver and ceremonial head. These are considered crucial roles for the educational administrators (Gorton, 1983). According to research into instructional enhancement, emphasis is also put on the role of leadership in helping organizations overcome crises by focusing on long-term benefits rather than short-term gains (Campbell, et al., 1993).

\section{Methodology}

A quantitative research approach was adopted. Data was collected from public vocational education administrators under the office of the vocational education commission in Thailand through a questionnaire. This research aims to study the characteristics, behaviors, and situational management of leaders which affect the sustainable leadership of vocational education with, and to bring the resulting empirical data to develop the sustainable leadership of vocational education administrators.

The population of this study included the vocational education administrators under the Office of The Vocational Education Commission in Thailand, with the sample group being the vocational education directors and vice directors under its jurisdiction.

The sample size was determined by considering parameters required to estimate the value used, with 20 persons per 1 parameter required to estimate the model of conceptual framework for this research. With 24 observable variables, the sample size used should number between 15-20 times of the observable variables (Lindeman et al. 1980) and hence the total samples used were 480 , selected by multistage sampling according to the proportion of population numbers of vocational education administrators from 413 institutions. $404(84.17 \%)$ questionnaires were completed and returned.

The instrument used for data collection was a Likert-scale questionnaire sent to respondents. Items concerning the behaviors of sustainable leadership of vocational education administrators were based on the concepts of Hargreaves and Fink (2006) with a rating scale of 5 levels: most, much, moderate, little, and least.

The sustainable leadership (STL) consisted of 7 components: the significance of sustainable leadership (STL1), the maintenance of sustainable leadership (STL2), the distribution of sustainable leadership (STL3), the justice of sustainable leadership (STL4), the realization and variance of sustainable leadership (STL5), the human resources development and resources maintenance of sustainable leadership (STL6), and the respect and learning from good experiences of sustainable leadership (STL7).

The factors affecting the sustainable leadership of vocational education administrators were comprised of a total of 4 factors: leaders' characteristics (CHR), situation management (STM), leaders' behaviors (BEH), and leaders' roles (ROL).

Items concerning leaders' characteristics (CHR) were based on the concepts of DeRue et al. 
(2011), Huglies and Hosfeld (2005), Visser and Courtice (2011) and Visser (2013), consisting of 5 observable variables: vision (CHR1), systematic thinking (CHR2), initiative (CHR3), emotional wisdom (CHR4), and collaboration (CHR5).

Items concerning Situation Management (STM) were based on the concepts of Fiedler and Garcia (1987), Evans (1970), House (1971) and Hoy and Miskel (1991), consisting of 4 observable variables: work structure (STM1), power in position (STM2), characteristics of subordinators (STM3), and organizational environments (STM4).

Items concerning Leaders' Behaviors (BEH) were based on the concepts of Bass (1990), Bass and Avolio (1994), Blake and Mouton (1964), DeRue et al. (2011), Reddin (1970) and Tichy and Devanna (1986), consisting of 4 observable variables: task-oriented (BEH1), people-oriented (BEH2), effectiveness-oriented (BEH3), and change-oriented (BEH4).

Items concerning Roles of Leader (ROL) were based on the concepts of Campbell et al. (1993), Gorton (1983) and Knezevich (1984), consisting of 4 observable variables: communicator (ROL1), problem and conflict solver (ROL2), academic leader (ROL3), and assessor (ROL4).

For the reliability analysis, Cronbach's method was utilized, with the coefficient value equal to 0.987. The statistical package SPSS 24.0 and AMOS 23 were used to analyze the quantitative data.

The measurement model and hypothesis are formulated for the exogenous (independent) variables and the endogenous (dependent) variables. The research model used in this study consists of four exogenous latent constructs, namely, "leaders' characteristics" (CHR), "situation management" (STM), "leaders' behaviors" (BEH), and "leaders' roles" (ROL) and one endogenous latent constructs, namely "sustainable leadership" (STL).

The conceptual model and its relationships can be seen in Figure 1.

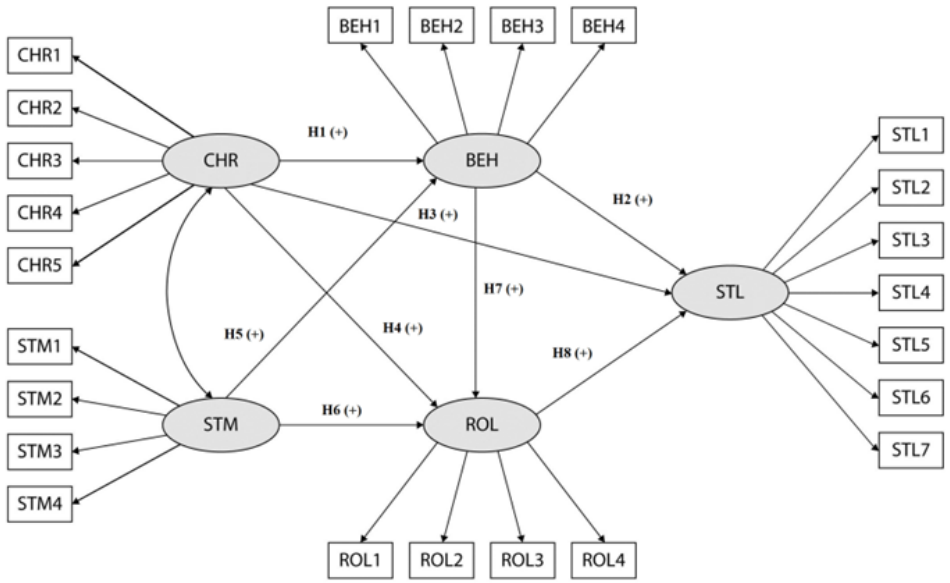

Figure 1. Conceptual model

\section{Results}

\subsection{Sample Characteristics}

According to the analysis results of primary data received from the sample group, $78.50 \%$ of the 404 respondents were male and $21.50 \%$ female, with $44.10 \%$ aged more than 54 years old, $33.70 \%$ aged between 45 to 54 years old and $18.10 \%$ aged between 35 to 44 years old. As for level of education, the majority of respondents, $79.2 \%$, were at Master's Degree level, with $12.1 \%$ at Bachelor's Degree level, and $8.7 \%$ at Doctorate Degree level. Regarding work experience, results indicate that most respondents, $51.20 \%$, worked for more than 24 years, $30.90 \%$ between 15 to 24 years, and $12.60 \%$ between 5 to 14 years. As for experience in an administrative position, $34.20 \%$ had experience of between 5 to 9 years, $26.2 \%$ less than 5 years, and $20.5 \%$ more than 14 years. 


\subsection{Structural Equation Models (SEM)}

SEM is a multivariate technique that examines simultaneously the series of dependence relationship of the hypothesized model. Basically, SEM combines multiple regression with confirmatory factor analysis (CFA) and has two mechanisms: the measurement model and structural model. According to Doloi, lyer, and Sawhney (2011), the measurement model is basically meant for the reliability and validity of the latent variables and observed variables; it checks the relationship between latent variables and observed variables. The structural model is concerned with the path strength and relationship among the latent variable.

The concordance examination concerning the hypothesis of relationship, the linear structure of the factors affecting the sustainable leadership of vocational education administrators and the empirical data, the path analysis was performed by AMOS Ver.23 Program, considered from the Chi Square $\left(\chi^{2}\right)$ which had no significance or $p$-value higher than 0.05 , CMIN/DF ( $\left.\chi^{2} / \mathrm{df}\right)$ which had a value not higher than 3.00, GFI Index (goodness-of-fit), AGFI Index (adjusted goodness-of-fit index) which had a value equal to or greater than 0.90 , RMSEA value (root mean square error of approximation) which had a value equal to or greater than 0.90 , and CFI (comparative fit index) which had a value equal to or greater than 0.90 , indicating that the model was in concordance (Kline, 2011).

\subsection{Results of Confirmatory Factors}

According to results from the examination of the validity of the measurement model for the 7 factors of sustainable leadership for vocational education administrators, all items used to measure each factor had statistical significance at 0.01 level for every value and therefore the question items could measure each factor. When considering each factor from the analysis results, $\chi^{2}=6.678, \mathrm{df}=$ $6, p=.343$, CMIN/DF $=1.128$, the Root Mean Square Error of Approximation (RMSEA) was equal to .018 , the Comparative Fit Index (CFI) was equal to 1.000 , the Goodness of Fit Index (GFI) was equal to .995, and the Adjusted Goodness of Fit Index (AGFI) was equal to .978, indicating that the model was consistent with the empirical data.

From the examination of the validity of the measurement model concerning the 5 leaders' characteristics, results indicated that every question item used for measuring each factor had statistical significance at 0.01 in every value and therefore every question item could measure each factor. When considering each factor, the analysis results revealed that $\chi^{2}=1.145, \mathrm{df}=3, p=.766$, $\mathrm{CMIN} / \mathrm{DF}=.382$, the Root Mean Square Error of Approximation (RMSEA) was equal to .000 , the Comparative Fit Index (CFI) was equal to 1.000, the

Goodness of Fit Index (GFI) was equal to .999, and the Adjusted Goodness of Fit Index (AGFI) was equal to .994, indicating that the model was consistent with the empirical data.

Regarding the examination of the validity of the measurement model concerning the 4 situational management factors, results show that every question item used to measure each factor had statistical significance at 0.01 in every value, so the question items could measure each factor. When considering each factor, the analysis results revealed that $\chi^{2}=.768$, df $=1, p=.381$, CMIN/DF $=.768$, the Root Mean Square Error of Approximation (RMSEA) was equal to .000, the Comparative Fit Index (CFI) was equal to 1.000, the Goodness of Fit Index (GFI) was equal to .999, and the Adjusted Goodness of Fit Index (AGFI) was equal to .990, indicating that the model was consistent with the empirical data.

For the examination of the validity of the measurement model concerning the 4 behavioral factors, results indicate that every question item used to measure each factor had statistical significance at 0.01 in every value, therefore the question items could measure each factor. When considering each factor, the analysis results showed that $\chi^{2}=5.284$, df $=2, p=.071, \mathrm{CMIN} / \mathrm{DF}=$ 2.642, the Root Mean Square Error of Approximation (RMSEA) was equal to .064, the Comparative Fit Index (CFI) was equal to .997, the Goodness of Fit Index (GFI) was equal to 993, and the Adjusted Goodness of Fit Index (AGFI) was equal to .967, indicating that the model was consistent with the empirical data.

And finally, according to the examination of the validity of the measurement model in respect to the 4 role factors, results revealed that every question item used to measure each factor also had 
the statistical significance at 0.01 in every value and were able to measure each factor. When considering each factor, the analysis results revealed that $\chi^{2}=2.875, \mathrm{df}=1, p=.090, \mathrm{CMIN} / \mathrm{DF}=$ 2.875, the Root Mean Square Error of Approximation (RMSEA) was equal to .068, the Comparative Fit Index (CFI) was equal to .999, the Goodness of Fit Index (GFI) was equal to .996, and the Adjusted Goodness of Fit Index (AGFI) was equal to .965, also showing that the model was consistent with the empirical data. The results mentioned above are detailed in Table 1.

Table 1. Goodness of fit statistics for the five confirmatory factor analyses performed

\begin{tabular}{lcccccccc}
\hline Model & $\chi^{2}$ & $\mathbf{d f}$ & $\mathbf{p}$ & CMIN/DF & RMSEA & CFI & GFI & AGFI \\
Sustainable leadership (7 factors) & 6.678 & 6 & .343 & 1.128 & .018 & 1.000 & .995 & .978 \\
Characteristic (5 factors) & 1.145 & 3 & .766 & .382 & .000 & 1.000 & .999 & .994 \\
Situational management (4 factors) & .768 & 1 & .381 & .768 & .000 & 1.000 & .999 & .990 \\
Behavioral (4 factors) & 5.284 & 2 & .071 & 2.642 & .064 & .997 & .993 & .967 \\
Role (4 factors) & 2.875 & 1 & .090 & 2.875 & .068 & .999 & .996 & .965 \\
\hline
\end{tabular}

\subsection{Results of Structural Equation Models}

The results of the concordance examination of the model developed by the researcher revealed the Chi Square being different from zero with no statistical significance $\left(\chi^{2}=199.999\right.$, $\mathrm{df}=185, p=$ .214 ,), the Root Mean Square Error of Approximation (RMSEA) was equal to 0.014 , the Comparative Fit Index (CFI) was equal to .998, the Goodness of Fit Index (GFI) was equal to 0.960, and the Adjusted Goodness of Fit Index (AGFI) was equal to 0.935, showing that the model was in accordance with the empirical data.

Concerning the overall effect sizes, results revealed that leaders' characteristics had the overall effect towards the sustainable leadership of vocational education administrators with statistical significance at $.01(\mathrm{p}<.01)$. The overall effect of the leaders' characteristics towards the sustainable leadership of vocational education administrators had an effect size coefficient value equal to .820. Likewise, the coefficient value of effect sizes for situational management was equal to. 071 , for leaders' behaviors equal to .119, and for leaders' roles equal to .056 , so it is evident that leaders' characteristics had the highest overall effects towards the sustainable leadership of vocational education administrators, as shown in Figure 2.

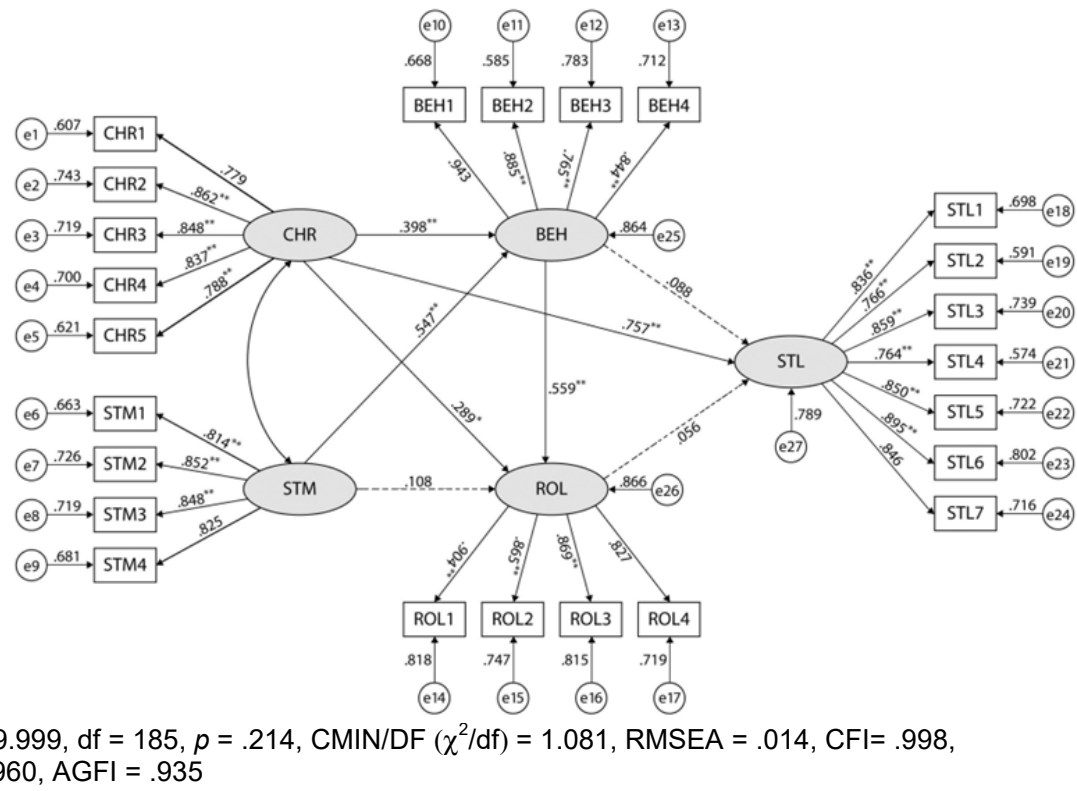

Figure 2. The Structural Equation Model of Sustainable Leadership 


\section{Discussion}

The size of the direct effects of the predictor variables for the sustainable leadership of vocational education administrators revealed that the characteristics of leaders had direct positive effects on the sustainable leadership of vocational education administrators that are statistically significant, whereas the leaders' behaviors and the leaders' roles had direct positive effects on the sustainable leadership of vocational education administrators without any statistical significance. The characteristics of the leaders had a direct effect towards the sustainable leadership of vocational education administrators with the effect size coefficient equal to $.757(p<.01)$.

The leaders' behaviors had a direct effect towards the sustainable leadership of vocational education administrators with the effect size coefficient value of .088 , and the leaders' roles had a direct positive effect towards the sustainable leadership of vocational education administrators with the effect size coefficient value equal to. 056. The leaders' characteristics had the highest direct effect towards the sustainable leadership of vocational education administrators, followed by the leaders' behaviors, and the leaders' roles, respectively.

Leaders' characteristics such as vision, systematic thinking, initiative, emotional wisdom, and increasing coordination would affect vocational education administrators and instill in them sustainable leadership by bolstering its components in terms of significance, maintenance, distribution, justice, realization, enhancement of variance on human resources development, resources maintenance, and respect and learning from the past with .01statistical significance.

As for resulting indirect effects, the leaders' characteristics had a statistically significant positive indirect effect towards the sustainable leadership of vocational education administrators (coefficient value of effect sizes was equal to .063, $p<.01$ ), whereas the positive indirect effects regarding situational management (coefficient value of effect sizes was equal to .071) and leaders' behaviors (coefficient value of effect sizes was equal to .031) had no statistical significance. Giving vocational education administrators support regarding leaders' characteristics such as vision, systematic thinking, emotional wisdom, and increasing coordination would instill and promote in them qualities of sustainable leadership (Stogdill, 1981; Huglies \& Hosfeld, 2005; Visser \& Courtice, 2011; Visser, 2013).

Introducing and reinforcing the components the sustainable leadership, maintenance of sustainable leadership, distribution of sustainable leadership, justice without harming others, realization and enhancement of the variance through human resources development and resources maintenance, and respect and learning from past experiences increased sustainable leadership by a statistical significance of .01 as well. The leaders' characteristics and situational management could explain the variance of the leaders' behaviors for vocational education administrators being at $86.4 \%$, whereas the leaders' characteristics and leaders' behaviors account for the variance of the leaders' roles for vocational education administrators being at $86.6 \%$, and the leaders' characteristics accounting for the variance of the sustainable leadership of vocational education administrators being at $78.9 \%$. Possessing and demonstrating leaders' characteristics such as vision, systematic thinking, emotional wisdom, and coordination would therefore positively affect and increase sustainable leadership in vocational education administrators.

Leaders' characteristics have a direct impact on the sustainable leadership of vocational education administrators. Have a systematic thinking process, being innovative and able to think outside of the box are important characteristics that contribute to sustainable leadership and consequently the sustainable development of the organization (Davies, 2007). To flourish in modern conditions, vocational education requires management possessing systematic thinking processes, innovation and unconventional thinking to lead organizations to stay abreast with and adapt to sociological and technological change. Administrators must set a vision for the institution to produce graduates who can master technology and innovate to meet the demands of the labor market.

The behavior of school administrators and leadership roles also significantly influences the sustainability of leadership. By having behavior that focuses on the needs and development of individuals and motivates positive change leaders demonstrate and promote sustainable leadership, as such behavior influences the performance of subordinates and delegates authority 
with the effect of producing other leaders as well (DeRue et al., 2011).

While the effects of situation management on the role of the administrators of vocational schools was not as comparatively insignificant as other factors, leaders still must manage situations appropriately and in accordance with the work structure of their institutions. The inherent power perceived in respect to administrative titles and positions impacts their relationships with others in the organization and leaders' skills in navigating issues such as communication, conflict management and the performance of their academic have a significant effect on the sustainable leadership of the administrators of vocational schools.

Thailand vocational school administrators need to understand the structure of their workplace and its hierarchies if they are to reasonably exercise authority as well as allow for the individual self-expression that helps to make educational institutions efficient, effective and sustainable. Leaders' systematic thinking processes, originality and innovation are important characteristics that directly impact person-centered leadership behavior and are geared towards significant change even though they had no statistically significant effect on the sustainable leadership of vocational school administrators. Both work-oriented and focus-oriented behavior affect the performance of supervisors (DeRue et al., 2011) and the characteristics of systematic thinking, originality, innovation, influence and coordination are significant because they enable management to set a vision for organizations to keep up with change. The role of communication, however, was shown to have no significant impact on leadership, perhaps because communication with subordinates and other educational institutions was not explicitly perceived as effective in sustaining educational institutions and facilitating situational management (Gorton, 1983; Knezevich, 1984).

Considering the ability to predict the dependent variables of the predictor variables, results indicate that every observable variable in the Structural Equation Models of sustainable leadership of vocational education administrators had significance at a similar level. The coefficient values of the weight of standard factors were between .766 - .943. The leaders' characteristics as factors affecting vocational education administrators increased sustainable leadership. All variables in the Structural Equation Models of sustainable leadership of vocational education administrators could explain the variance of the sustainable leadership of vocational education administrators at $78.9 \%$.

\section{Conclusion}

Leaders' characteristics had overall effects towards the sustainable leadership of vocational education administrators by a statistical significance of $.01(p<.01)$ and the effect size coefficient value equal to .820. Leaders' situational management had overall effects towards the sustainable leadership of vocational education administrators with the effect size coefficient value equal to .071, leaders' behaviors had overall effects towards the sustainable leadership of vocational education administrators with the effect size coefficient value equal to.119, and leaders' roles had overall effects towards the sustainable leadership of vocational education administrators with the effect size coefficient value equal to. 056. From the research, leaders' characteristics had the highest overall effects towards the sustainable leadership of vocational education administrators.

The ability to predict the dependent variables of the predictor variables found that all observable variables in the Structural Equation Models of sustainable leadership of vocational education administrators had significance at a similar level, with the coefficient value of the weight of standard factors between .766 - .943. All variables in the structural equation models of sustainable leadership of vocational education administrators account for the variance of the sustainable leadership development of vocational education administrators at $78.9 \%$. Leaders' characteristics was the factor which most significantly affected the vocational education administrators and increased their sustainable leadership although other factors, while less statistically significant, also offer value in effective leadership.

\section{References}

Abrahamson, E. (2004). Change without pain: How managers can overcome initiative overload, organizational chaos, and employee burnout, Boston, MA: Harvard Business School Press. 
Bass, B.M. (1985). Leadership and performance beyond expectations, New York: The Free Press.

Bass, B. M. (1990). From transactional to transformational Leadership: Learning to share the vision. Organizational Dynamics, 18(3), 19-31.

Bass, B. M. \& Avolio, B. J. (1994). Improving Organization Effectiveness Through Transformational Leadership, Thousand Oaks: Sage.

Blake, R. R. \& Mouton, J. S. (1964). The Managerial Grid, Houston: Gulf Publishing Company.

Campbell, J. P., McCloy, R. A., Oppler, S. H., \& Sager, C. E. (1993). A theory of performance. In E. Schmitt, W. C. Borman, \& Associates (Eds.), Personnel selection in organizations (pp. 35-70), San Francisco: Jossey-Bass.

Covey, S. R. (2004). The 7 habits of highly effective people: Restoring the character ethic, New York: Free Press.

Davies. B. (2007). Developing sustainable leadership, London: Sage.

DeRue, S. D., Nahrgang, J. D., Wellman, N., \& Humphrey, S. E. (2011). Trait or Behavioral Theories of Leadership: An integration and meta-analytic test of their relative validity. Personnel Psychology, 64, 7-52.

Doloi, H., lyer, K. C., \& Sawhney, A. (2011). Structural equation model for assessing impacts of contractor's performance on project success. International Journal of Project Management, 29, 687-695.

Ellis, J. R., \& Hartley, C. L. (2001). Nursing in today's world: Challenges, issue and trends (7th ed.), Philadelphia: Lippincott.

Evans, M. G. (1970). The Effects of Supervisory Behavior on the Path-Goal Relationship." Organizational Behavior and human performance. 5, 277-298.

Fiedler, F.E. \& Garcia, J.E. (1987). New approaches to effective leadership: Cognitive resources and organizational performance, New York: Wiley.

Fiedler, F., \& Chemers, M. M. (1974). Improving leadership effectiveness: The leader match concept (Rev. ed.), New York: Wiley.

Fullan, M. (2001). Leading in a culture of change, San Francisco: Jossey-Bass.

Gorton, A. R. (1983). School Leadership and Administration: Important Concepts, Case Studies, and Simulations, Dubuque, lowa: Wm. C. Brown.

Grooms, L. D., \& Reid-Martinez, K. (2012). Leadership Development: Bridging Culture through Communication, Mentoring, and Constructivism. Presented at the 14th annual International Leadership Association Conference, Denver, CO, October 2012.

Haque, M. D. , Titi Amayah, A. \& Liu, L. (2016). The role of vision in organizational readiness for change and growth. Leadership \& Organization Development Journal, 37(7), 983-999.

Hargreaves, A. \& Fink, D. (2006). Sustainable leadership, San Francisco: Jossey-Bass.

Hargreaves, A. \& Fink, D. (2004). The Seven Principles of Sustainable Leadership." Educational Leadership, 61(7), 8-13.

Hargreaves, A. \& Goodson, I. (2004). Change over time? A report of educational change over 30 years in eight U.S. and Canadian schools, Chicago: Spencer Foundation.

Hellriegel, D., Slocum, J.W. \& Woodman, R.W. (2001). Organizational behavior ( ${ }^{\text {th }}$ ed.), Australia: SouthWestern College.

Hersey, P. \&. Blanchard, K.H. (1982). Management of organization behavior: utilizing human resources $\left(4^{\text {th }}\right.$ ed.), Englewood Cliffs. NJ: Prentice-Hall.

Hersey, P., Blanchard, K. H., \& Johnson, D. E. (1996). Management of Organizational Behavior (7th ed.), Upper Sandle River, NJ: Prentice-Hall.

House, R.J. 1971. A Path-goal theory of leadership Effectiveness. Journal of Contemporary Business. 16, 321328.

Hoy, Wayne. K \& Cecil G. Miskel. (1991). Educational Administration: Theory Research and Practice (4 ${ }^{\text {th }}$ ed.), New York: Harper Collins.

Huglies P. \& Hosfeld K. (2005). The Leadership of Sustainability A study of characteristics and experiences of leaders bringing the "triple-bottom line" to business, Seattle: Center for Ethical Leadership.

International Institute for Management Development. (2014). IMD releases its 2014 World Competitiveness Yearbook Ranking. Retrieved from: http://www.imd.org/news/2014-World-Competitiveness.cfm.

Kline, R. B. (2011). Principles and practice of structural equation modeling ( $3^{\text {rd }}$ ed.), New York: Guilford Press.

Knezevich, S. J. (1984). Administration of Public Education. $\left(4^{\text {th }}\right.$ ed.), New York: Harper and Row.

Lambert, S. (2011). Sustainable leadership and the implication for the general further education college sector. Journal of Further and Higher Education. 35(1), 131-148.

Lambert, S. (2012). The perception and implementation of sustainable Leadership strategies in further education colleges. Journal of Leadership Education. 11(2), 102- 120.

Lindeman, R. H., Marenda, P. F. \& Gold, R. Z. (1980). Introduction to Bivariate and Multivariate Analysis, Glenview, Illinois: Scott, Foreman and Company.

Lipham, J. M. (1998). Getzel's model in educational administration. Norman J. Boyan (ed.), Handbook of research on educational administration,. New York: Longman. 
Northouse, G. (2007). Leadership theory and practice. ( $3^{\text {rd }}$ ed.), Thousand Oak, London, New Delhe, Sage Publications, Inc.

Owens, R. G. (1981). Organization behavior in education, Englewood Cliffs, New Jersey: Prentice-Hall.

Reddin, W. J. (1970). The 3-D management style theory: Theory paper 2, Canada: Social Science System.

Stogdill, R. M. (1974). Handbook of leadership: A survey of the literature, New York: Free Press.

Stogdill, R.M. (1981). Stogdill's handbook of leadership (B.M. Bass, Ed.), New York: Free Press.

Stoner, J.A.F. \& Freeman, R E. (1989). Management. (4 ${ }^{\text {th }}$ ed.), Prentice-Hall, Inc., New Jersey.

Tichy, N. M. \& Devanna, M. A. (1986). The transformational leader, New York: Wiley.

Visser, W. (2013). The 7 habits of effective sustainability leaders. CSR International Inspiration Series. No. 12.

Visser, W. \& Courtice, P. (2011). Sustainability leadership: Linking theory and practice. SSRN Working Paper Series, 21 October 2011. Published on SSRN at: http://ssrn.com/abstract=1947221.

Yukl, G. (2010). Leadership in Organizations. (7th ed.), New Jersey: Prentice Hall. 